\title{
UMA REFLEXÃO DA VISÃO DE DJAMILA RIBEIRO E SÍLVIO DE ALMEIDA SOBRE O RACISMO
}

\author{
Marcos Antônio Apolinário Mendes \\ Universidade Estadual de Goiás - UEG. \\ E-mail: strongmark@bol.com.br \\ Dulce Pereira dos Santos \\ Universidade Estadual de Montes Claros - UNIMONTES. \\ E-mail: dulce.santos@unimontes.br
}

\section{RESUMO}

O tema deste artigo é o racismo existente no Brasil sob visão de dois importantes autores da atualidade (2020) Djamila Ribeiro e Sílvio de Almeida. Ambos escreveram dois importantes livros que constituem referências para a educação antirracista. Os livros são o Pequeno Manual Antirracista e Racismo Estrutural. O objetivo deste estudo é apresentar uma análise da luta antirracista constante nas obras e também presenciados por todos no Brasil. Utilizamos como metodologia a revisão bibliográfica e análise do posicionamento dos autores sobre o racismo intercalando com as experiências. Os resultados desse estudo indicam que a luta contra o racismo deve ser contínua.

Palavras-chave: Racismo. Antirracismo. Djamila Ribeiro. Sílvio Almeida.

\section{INTRODUÇÃO}

Quantos de nós já não presenciamos, vivenciamos ou ouvimos de alguém que tenha sofrido uma situação racista? Ou quem não ficou indignado ao saber que uma pessoa negra tenha sido tratada assim? As pessoas têm se lamentado por tais fatos desde que o Brasil foi descoberto. Entretanto, indagamos o tempo que nossa sociedade ainda permitirá que o racismo faça parte dela e macule nossa história e nosso legado como nação, se somos considerados um país da pluralidade, da diversidade cultural, e se a população negra é a maioria dos brasileiros.

O Brasil foi um país formado por três culturas: a europeia, através dos portugueses em suas caravelas, a indígena, pelos silvícolas que aqui já estavam antes de sua descoberta, e, por fim, os africanos, trazidos como escravos para trabalharem em terras coloniais. E ao relembrarmos isso, muitos não têm do que se orgulhar, pois, nossa nação começou com um capítulo muito triste chamado "escravidão", onde capturavam e traziam a força os negros, que eram obrigados a deixar para trás suas famílias, suas terras, seus legados e o principal, sua liberdade. Eles não tinham valor como ser humano e eram vendidos como mercadorias ou capturados e levados de suas terras natais. Observe o que narra o artigo de Silva retirado da revista eletrônica Brasil Escola a esse respeito: 
Os escravos eram conseguidos por traficantes que obtinham os prisioneiros comprando-os, caso fossem prisioneiros de guerra, ou por meio de emboscadas realizadas pelos próprios traficantes. Os africanos, após terem sido feitos prisioneiros, eram levados a pé até os portos onde seriam revendidos para os portugueses (ou outros europeus). Nesses portos, os africanos eram marcados com ferro quente para identificá-los de qual comerciante eram. (SILVA, 2020, p. 2).

É muito triste pensar que a origem da nação brasileira tenha sido iniciada às custas do suor, sangue e sofrimento de um povo. Porém, existem muitas pessoas que têm tentado mudar as concepções acerca da inserção da cultura negra em nossa sociedade, e não apenas lembrá-la como parte de uma sociedade escravocrata. Refletiremos a seguir as ideias de Djamila Ribeiro e Sílvio de Almeida, importantes autores que discutem esse tema no Brasil, de forma bem didática e atuante. São autores referência, críticos, reflexivos e conseguem despertar em quem lê, a necessidade de desenvolver uma educação antirracista.

\section{DESENVOLVIMENTO}

Djamila Thaís Ribeiro dos Santos, conhecida apenas como Djamila Ribeiro, escritora, pesquisadora, mestra em Filosofia Política pela Universidade Federal de São Paulo e ativista pelos direitos dos negros e de sua cultura, é uma das pessoas que lutam para acabar com o racismo e mostrar que existe uma cultura negra rica, com identidade própria, que ensina, que tem opiniões, que produz pensamentos e literatura, que faz parte do Brasil e que, acima de tudo, quer ter voz e vez. Ela é conhecida pelo seu ativismo em defesa dos direitos dos negros e de sua cultura, em sua obra Pequeno Manual Antirracista (2019), que expõe fatos de sua vida e busca caminhos para que os negros tenham oportunidades em uma sociedade que impõe equivocadamente a cultura "branquicista".

Diante disso, o uso da terminologia "branquicista" não existe, mas é apenas um neologismo criado propositadamente para mostrar que, assim como alguns termos não existem, outros também não deveriam existir em nosso vocabulário e em nossas atitudes, e um deles é o "racismo", que abordaremos a seguir.

Quando o assunto em questão se trata de racismo ou esse é o tema em debate, existem aqueles que realmente são racistas assumidos e não tem o menor interesse em escondê-lo, porém, existem aqueles que dizem que não são racistas de jeito nenhum, mas, que na verdade são. Isso pode ocorrer sem que eles percebam, ou seja, de forma involuntária, em seus pensamentos, em certas atitudes, nos vocabulários que utilizam, 
nas escolhas que fazem ou no modo como se relacionam com aqueles que consideram, eu não sei por qual motivo, como sendo uma raça inferior.

Mas qual é a origem do racismo ou por que ele ainda acontece? A resposta teremos de quem entende do assunto - Djamila Ribeiro (2019). A autora defende que ele é fruto de uma construção estrutural e histórica do Brasil, e, consequentemente, estaria o fato da cultura branca ser privilegiada socialmente e economicamente, ao contrário da cultura negra.

O primeiro ponto a entender é que para falar de racismo no Brasil é, sobretudo, fazer um debate estrutural. É fundamental trazer a perspectiva histórica e começar pela relação entre escravidão e racismo, mapeando suas consequências. Deve-se pensar como esse sistema beneficiando economicamente por toda história a população branca, ao passo que a negra, tratada como mercadoria, não teve acesso a direitos básicos e à distribuição de riquezas. (RIBEIRO, 2019, p. 5).

Infelizmente, a estrutura política e histórica produzida pela ideologia branquicista, ou seja, da "branquitude" ao longo da formação da cultura brasileira, fizeram com que as pessoas dessem lugar ao racismo e valorizassem os hábitos e a cultura da branquitude em detrimento da cultura negra. Com isso, como resultado, todos os seguimentos de nossa sociedade, como educativo, empregatício, profissional, político e artístico foram dominados pela branquitude, e fazem com que eles tenham mais oportunidades, por se tratar de uma divisão social que se perpetua como um sistema de discriminação social (Ribeiro, 2019, p. 10).

Conforme uma pesquisa apresentada pela autora, a "população negra representa 56\% da população brasileira" (RIBEIRO, 2019, p. 13), então, o que fazer para que os negros possam ter mais espaço nos seguimentos sociais dominados pela maioria branca? A resposta está, além do combate ao racismo, na "educação, pois seria através das políticas educacionais afirmativas, como bolsas de estudos e cotas raciais" (RIBEIRO, 2019, p.18), por exemplo, que os negros teriam mais oportunidades à uma educação de qualidade, se formariam, entrariam no mercado de trabalho e, consequentemente, aumentariam suas participações em todos os setores produtivos da sociedade, os quais foram mencionados anteriormente. Consequentemente, sem estudar, fazer um curso superior, se especializar e se profissionalizar, ficaria mais difícil derrubar as barreiras sociais existentes e impostas pela cultura da branquitude.

Outra questão que Ribeiro expõe com relação ao racismo diz respeito à cultura negra. Segundo ela, infelizmente, "as culturas indígenas e negras foram expropriadas e 
apropriadas historicamente pela cultura branca" (RIBEIRO, 2019, p. 25). Esse fato também tem influenciado e contribuído para o crescimento do racismo no país, fruto de o fato dos brancos tentarem impor sua cultura, de origem europeia, acima da cultura afrodescendente e indígena. Sendo assim, a autora afirma que a "solução seria valorizar a cultura negra e apoiar autores negros" (RIBEIRO, 2019, p. 23-24).

Como se pode observar, a visão de Djamila Ribeiro (2019) sobre o racismo nos expõe à dura realidade do racismo estar emaranhado nas camadas da nossa sociedade, trazendo grandes danos à vida do negro e sua cultura, afetando seu convívio e suas oportunidades sociais, educacionais, culturais e financeiras. Sendo assim, é lamentável saber que nosso país tem criado leis e elaborado políticas tão insignificantes para aqueles que tiveram uma parte importante e contribuíram para sua existência como nação com identidade própria.

É importante ressaltar que outras visões sobre o racismo são expostas no cenário brasileiro, dentre eles destaca-se também além de Djamila Ribeiro, Sílvio de Almeida. Escritor negro, advogado, filósofo, doutor e pós doutor em Direito pela faculdade de Direito da Universidade de São Paulo, Diretor presidente do Instituto Luiz Gama e professor de várias universidades brasileiras. Em seu livro Racismo Estrutural expõe que a segregação não oficial entre negros e brancos existentes na sociedade desafia algumas explicações.

1. Pessoas negras são menos aptas para a vida acadêmica e para a advocacia;

2. Pessoas negras, como todas as outras pessoas, são afetadas por suas escolhas individuais, e sua condição racial nada tem a ver com a condição socioeconômica;

3. Pessoas negras, por fatores históricos, têm menos acesso à educação e, por isso, estão alocadas em trabalhos menos qualificados, os quais, consequentemente, são mal remunerados;

4. Pessoas negras estão sob o domínio de uma supremacia branca politicamente construída e que está presente em todos os espaços de poder e prestígio social (ALMEIDA, 2020, p. 61).

De acordo com Almeida (2020) as duas primeiras afirmações são racistas. Sendo que o autor ressalta que a primeira explicação é racista, pois é como se as pessoas negras fossem uma espécie de inferioridade natural. A segunda afirmação também é racista, como se os negros fossem os culpados pelas próprias mazelas. Em relação a terceira e quarta explicação, o autor revela que:

[...] trazem o que podemos chamar de meias verdades. De fato, negros e negras são considerados o conjunto da população brasileira, apresentam menor índice de escolaridade e, sim, o sistema político e econômico privilegia pessoas consideradas brancas. Mas o que as explicações três e 
quatro não mostram é o motivo pelo qual pessoas não brancas têm menos acesso à educação e como e por que pessoas brancas obtêm vantagens e privilégios sociais (ALMEIDA, 2020, p. 62).

Ainda acompanhando essa discussão atualmente (2020), questões importantes nos levam a algumas indagações: Porque naturalizamos tanto a discriminação racial? Porque demoramos tanto a perceber essa desigualdade tão presente em nossa sociedade? Porque a população em geral utiliza tanto as expressões e palavras que exprimem o racismo? Seria falta de conhecimento? Ou mesmo depois de conhecermos o real significado dessas expressões, continuamos a usar?

No livro de Almeida (2020), encontramos discussões interessantes porque o autor perpassa o tema racismo interligando com a ideologia, a política e a economia. Destacamos alguns detalhes em cada item analisado. Percebemos que quando o autor faz a relação do racismo com a ideologia, fica claro que ideologia seria um conjunto de ideias estabelecendo pensamentos e valores que no caso aqui discutido voltado para as ideias do racismo. Segundo Almeida (2020):

O racismo constitui todo um complexo imaginário social que a todo
momento é reforçado pelos meios de comunicação, pela indústria cultural e
pelo sistema educacional. Após anos vendo telenovelas brasileiras, um
indivíduo vai acabar se convencendo de que mulheres negras Têm uma
vocação natural para o trabalho doméstico, que a personalidade de homens
negros oscila invariavelmente entre criminosos e pessoas profundamente
ingênuas, ou que homens brancos sempre tem personalidades complexas e
são líderes natos, meticulosos e racionais em suas ações (ALMEIDA, 2020,
p. 65).

Mas se prestarmos bastante atenção a realidade é essa mesma, isso é o que presenciamos, ou seja, esse é o imaginário que é reproduzido no dia a dia. Quanto ao racismo e política destacamos que nessas eleições de 2020 aumentaram a representatividade dos negros e isso pode ser considerado o resultado de anos de lutas. Mas não tenhamos a ilusão, como frisa Almeida (2020), que o fato de uma pessoa negra estar no poder não significa necessariamente que a população negra também esteja no poder.

Quando falamos de racismo e economia, estamos falando de desigualdade, pois ser negro acaba sendo um determinante da desigualdade econômica e social. Em geral o salário da população negra é menor quando comparado à população branca, dentre outras desigualdades existentes.

Enfim, racismo estrutural seria, então, segundo o Portal de Brasil de Direitos, “a naturalização de ações, hábitos, situações, falas e pensamentos que já fazem parte 
da vida cotidiana do povo brasileiro, e que promovem, direta ou indiretamente, a segregação ou o preconceito racial".

Dessa forma os dois autores negros analisados nesse trabalho discutem e proporcionam reflexões importantes sobre o racismo. Para eles, Almeida (2020) e Ribeiro (2019), a forma como a sociedade é conduzida reproduz os parâmetros da discriminação racial nos vários setores/segmentos da sociedade.

\section{CONSIDERAÇÕES FINAIS}

Finalizamos esse trabalho um dia após o assassinato de um homem negro, 40 anos no estacionamento de um importante supermercado em Porto Alegre (RS), as manifestações em todo o país foram e estão sendo numerosas, além da indignação acender uma esperança de prováveis mudanças, claro que bem lentamente, por isso que não podemos deixar de lutar pelo antirracismo, como diz o tema desse evento "percebendo o racismo internalizado em mim, em nós".

Portanto, a entende-se que, infelizmente, o racismo existe sim, e não basta fechar os olhos diante dele ou dizer que não é racista, é preciso mudar nossas concepções, ter atitudes positivas e amigáveis perante os negros, lutar contra e qualquer forma de discriminação e ajudá-los a encontrar seu lugar e seu espaço em uma cultura que não é somente do branco, do índio ou do negro, mas de todos nós, pois se o negro existe e é gente, precisa ter vez, ter voz e ter direito de usufruir também de tudo o que o Brasil tem a oferecer aos seus filhos, sem distinção de raça, de credo, de gênero ou de cor, principalmente uma educação antirracista que promova a igualdade.

\section{REFERÊNCIAS}

ALMEIDA, S. L. de. Racismo Estrutural. São Paulo: Editora Jandaíra, 2020.

BATISTA, W. M. A inferiorização dos negros a partir do racismo estrutural. Rio de Janeiro: Práxis, 2018.

RIBEIRO, D. Pequeno Manual Antirracista. São Paulo: Companhia das Letras, 2019.

SILVA, D. N. Tráfico negreiro: Brasil Escola. Disponível em: $<$ https://brasilescola.uol.com.br/historiab/trafico-negreiro.htm> Acessado em $21 \mathrm{de}$ outubro de 2020. 